\title{
The kinetic parameters of aerosols formed during combustion of modified wood
}

\author{
Feodor Portnov ${ }^{*}$ \\ Moscow State University of Civil Engineering, Yaroslavskoe shosse, 26, Moscow, 129337, Russia
}

\begin{abstract}
The paper studies kinetic properties of aerosols formed in thermal degradation of wood. The impact of modifying agents in wood surface layer on the quantitative composition of smoke aerosol solids was analyzed. For this purpose, grain-size of aerosol solids was analyzed, and the physical and chemical properties of source and modified wood were assessed.
\end{abstract}

\section{Introduction}

One of the most hazardous factors causing humans' death in a fire is smoke formation. As a result of the combustion of flammable construction materials, smoke formation in evacuation routes occurs, causing possible visibility deterioration that can lead to disorientation in space and panic under the increased hazard conditions. In addition, toxic substances forming combustion products can produce different effects on humans: from minor irritation of upper respiratory tract during short-term inhalation up to severe lung damages.

Modern scientific works are aimed at studying the influence of the wood species and various methods of its modification on smoke formation, which is characterized by the indices of decreasing light transmission capacity. One of the most effective ways to reduce the smoke-forming ability is the use of effective flame-retardants involved in the adsorption and chemical reaction in the surface layer of wood, thereby simultaneously reducing the fire hazard of wood. The issue of the effect on the structure and properties of the smoke aerosol is poorly investigated. Obviously, the study of this issue is urgent to ensure humans' safety in the event of a fire [1,2].

It is known that in case of thermal degradation of wood materials, the aerosol formation mechanism consists of several processes. Primary soot particles are formed due to incomplete combustion of the material. This is due to a low temperature at the initial stage of the thermal degradation of wood, resulting in the smoldering of wood parallel to the grain, with the release of incompletely degraded products into the ambient air. At high temperatures, the products of incomplete thermal degradation partially emit from fractures forming in the material surface, from deeper layers, due to the insufficient oxygen content in these layers [3-11].

\footnotetext{
Corresponding author: wastingtimefilmart@gmail.com
} 
The largest contribution to reducing visibility in a fire is made by aerosol particles forming as a result of diffusion of solids of a surface carbonized wood layer into the atmosphere due to convective flows at elevated temperatures. When thermal degradation of wood occurs, the formation of a surface carbonized layer consisting of thermally decomposed solids takes place. The possibility of diffusion of particles into the atmosphere during thermal degradation depends primarily on the structure and the strength of the carbonized layer [12-15].

It is evident that the properties and the structure of the surface layer of wood produce a significant effect on the smoke formation process during material combustion.

Based on the above mentioned, the objective of this paper is to evaluate the effect of wood surface layer modifiers on the smoke aerosol formation and stability. For this purpose, it is necessary to solve the following tasks: to determine the quantitative characteristics of the smoke aerosols formed during thermal degradation of the source and modified wood, as well as to assess the effect of modifiers on the structure and properties of the surface layer of wood during its thermal degradation.

\section{Methods and materials}

A well-known quantitative method of estimating the properties of the smokes formed during combustion of solid materials is the determination of the smoke-generating rate in accordance with GOST $12.1 .044-89 \mathrm{cl} .4 .18$

To quantify smoke aerosol, it is proposed to combine the granulometric analysis of the smoke solid phase with the use of the Cilas 1180 particle size analyzer and physical and chemical methods for estimating the surface layer of wood: elemental analysis with the use of the Quanta 200 scanning microscope, electron microscopy, and a method for estimating energy characteristics of a surface layer of modified wood before and after thermal degradation, using the EasyDrop contact angle detection device and Quantachrome NOVA $4200 \mathrm{e}$ unit for determining the specific area of samples.

Surface layer modifying agents are selected in line with previous papers in the area of fire protection of wooden construction materials by means of a surface chemical modification.

20\%-phosphite solutions: dimethyl phosphite (DMF), diethylphosphite (DEP), dibutyl phosphite (DBP), diphenyl phosphite (DFP), ammonium polyphosphate (APP-1) were used as modifiers of the surface layer of woodse $170 \times 250 \mathrm{~mm}$ paper size (W x H mm) and adjust the margins to those shown in the Table 1 . The final printed area will be $130 \times 210$ $\mathrm{mm}$. Do not add any page numbers.

\section{Results}

The initial assessment of the smoke-forming capacity according to GOST $12.1 .044-89$ is shown in Figure 1. 


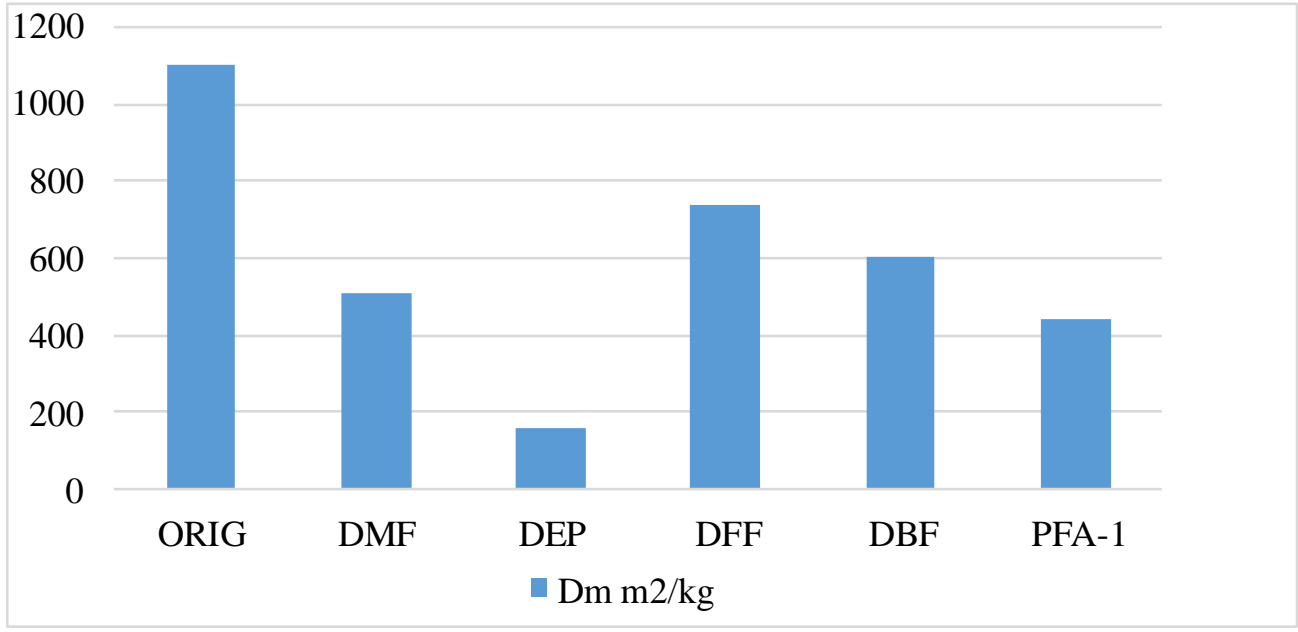

Fig. 1. Smoke-forming capacity of source and modified wood.

Following the results of the granulometric analysis and based on the mathematical calculations, the distribution of solid phase particles of the smoke aerosol was determined in accordance with the size of the modifier of the wood surface layer (Figure 2).

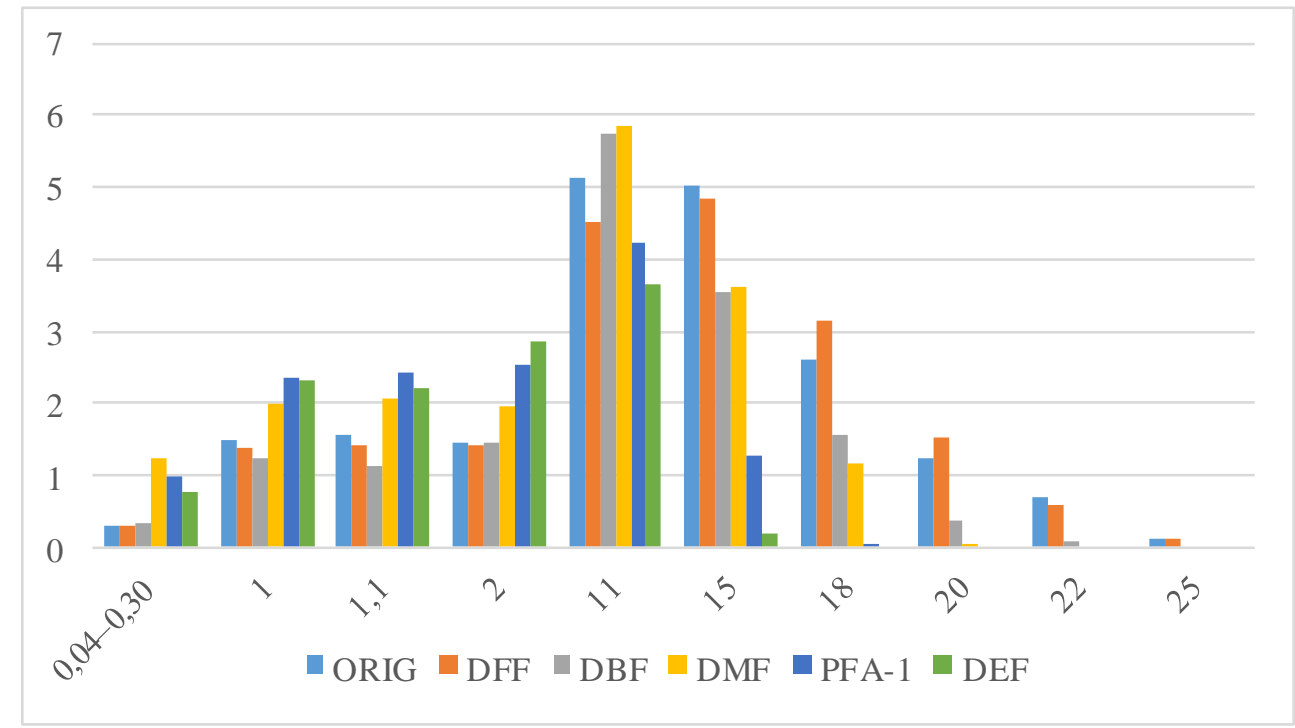

Fig. 2. Size distribution of aerosol disperse phase solids

To evaluate the stability of aerosols, it is necessary to determine its kinetic parameters: coagulation rate and sedimentation rate, which are determined by the structure of solid particles in the disperse phase and the Brownian motion [16-21]. Sedimentation rate is determined by the equation (1), where $r$ is the radius of solids in the aerosol disperse phase, $\rho$ is particles density, $\mathrm{g}$ is gravity factor and $\mu$ is medium viscosity $(\mu=1.81 \cdot 10-4 \mathrm{~Pa} \cdot \mathrm{s})$.

$$
W_{g}=2 r^{2} \cdot \rho_{z} \cdot g / 9 \mu
$$

Based on Brownian motion, coagulation speed is expressed by the equation (2), where $\mathrm{N}$ is the number of particles with radius, $\mathrm{A}$ is Stokes-Cunningham correction factor, $\mathrm{K}$ is 
Boltzmann constant, $\mathrm{T}$ is ambient temperature $(\mathrm{T}=70 \mathrm{oC})$, and 1 is free molecule path $(1=65.3 \mathrm{~nm})$.

$$
d N / d \tau=4 K \cdot T(1+A \cdot l / r) \cdot N^{2}
$$

The number of particles of the solid aerosol disperse phase was obtained based on the mass of the solid aerosol disperse phase and the particle size distribution. The results of calculating the kinetic parameters of the aerosol are presented in Table 1.

Table 1. Sedimentation rate and coagulation rate of aerosol solids.

\begin{tabular}{|c|c|c|c|c|c|c|c|}
\hline \multirow{3}{*}{$\begin{array}{c}\mathrm{R}, \\
\mu \mathrm{m}\end{array}$} & \multirow{3}{*}{$\mathrm{W}_{\mathrm{g}}, \mathrm{m} / \mathrm{s}$} & \multicolumn{6}{|c|}{ The speed of the coagulation of aerosol particulate matter during combustion of } \\
\hline & & \multirow{2}{*}{$\begin{array}{c}\text { original } \\
\text { wood }\end{array}$} & \multicolumn{5}{|c|}{ wood modified by } \\
\hline & & & DMF & DEP & DFF & DBF & PFA-1 \\
\hline 0,2 & $2,16 \cdot 10^{-7}$ & $1,40 \cdot 10^{-8}$ & $3,17 \cdot 10^{-8}$ & $5,76 \cdot 10^{-8}$ & $1,10 \cdot 10^{-8}$ & $2,0 \cdot 10^{-8}$ & $1,6 \cdot 10^{-7}$ \\
\hline 3,0 & $4,87 \cdot 10^{-5}$ & $1,51 \cdot 10^{-10}$ & $2,69 \cdot 10^{-10}$ & $2,67 \cdot 10^{-10}$ & $3,80 \cdot 10^{-10}$ & $1,0 \cdot 10^{-9}$ & $3,9 \cdot 10^{-10}$ \\
\hline 10,0 & $5,40 \cdot 10^{-4}$ & $9,16 \cdot 10^{-12}$ & $1,10 \cdot 10^{-11}$ & $5,20 \cdot 10^{-12}$ & $8,50 \cdot 10^{-12}$ & $1,5 \cdot 10^{-11}$ & $1,0 \cdot 10^{-11}$ \\
\hline 15,0 & $1,20 \cdot 10^{-3}$ & $1,99 \cdot 10^{-12}$ & $1,14 \cdot 10^{-12}$ & $1,70 \cdot 10^{-15}$ & $2,34 \cdot 10^{-12}$ & $1,5 \cdot 10^{-12}$ & $1,4 \cdot 10^{-13}$ \\
\hline \multicolumn{2}{|c|}{$\Delta \mathrm{m}, \mathrm{g}$} & 2,60 & 2,30 & 1,55 & 2,45 & 2,74 & 2,25 \\
\hline
\end{tabular}

The results of physical and chemical methods for estimating the surface layer of the source and modified wood are presented in Table 2 and in Figure 3 [22-24].

Table 2. The phosphorous content in the surface layer of wood before and after thermal decomposition.

\begin{tabular}{|l|c|c|c|c|c|}
\hline \multirow{2}{*}{ Condition of wood } & \multicolumn{5}{|c|}{ Phosphorus contents in wood modified by, \% } \\
\cline { 2 - 6 } & DMF & DEP & DBF & DFF & PFA-1 \\
\hline Before thermal decomposition & 2,87 & 3,57 & 2,65 & 2,45 & 2,11 \\
\hline After thermal decomposition & 0,85 & 4,70 & 0,71 & 1,06 & 0,35 \\
\hline
\end{tabular}

\section{$\Delta \mathrm{G}, \mathrm{kJ}$}

\section{0}

15

10

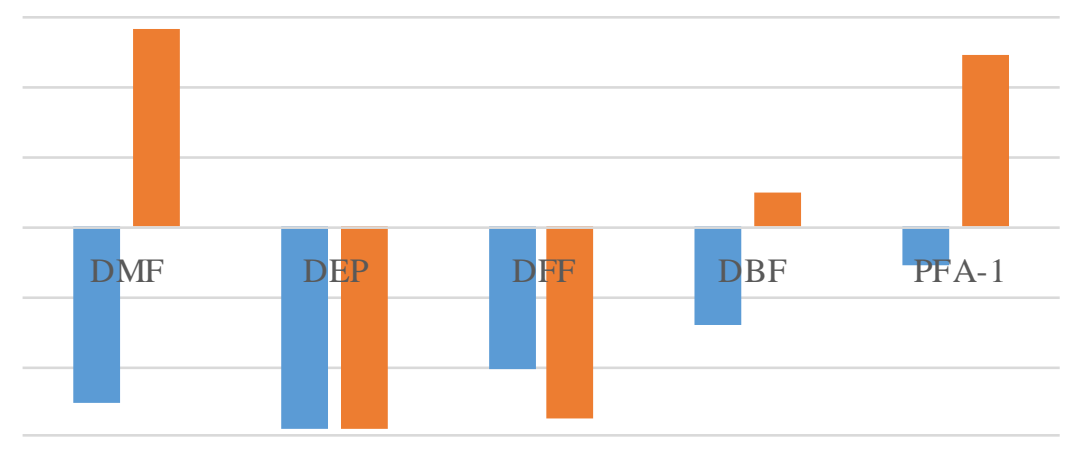

$-15$

$-20$

\section{before combustion after combustion}

Fig. 3. Energy characteristics of the modified wood surface 
Images of the surface of the carbonized layer of modified wood after thermal degradation are shown in Figure 4-7.

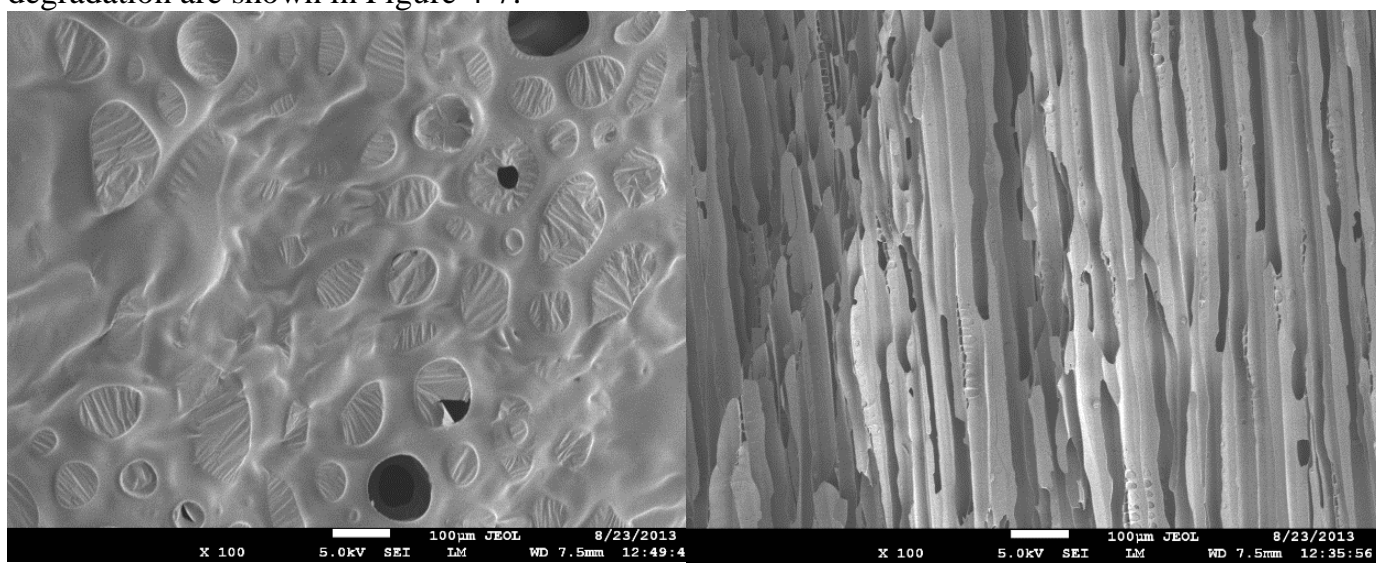

Fig. 4. Carbonized surface of the wood modified by DMF at magnification of $\mathrm{x} 200$
Fig. 5. Carbonized surface of the wood modified by DEF at magnification of x 200

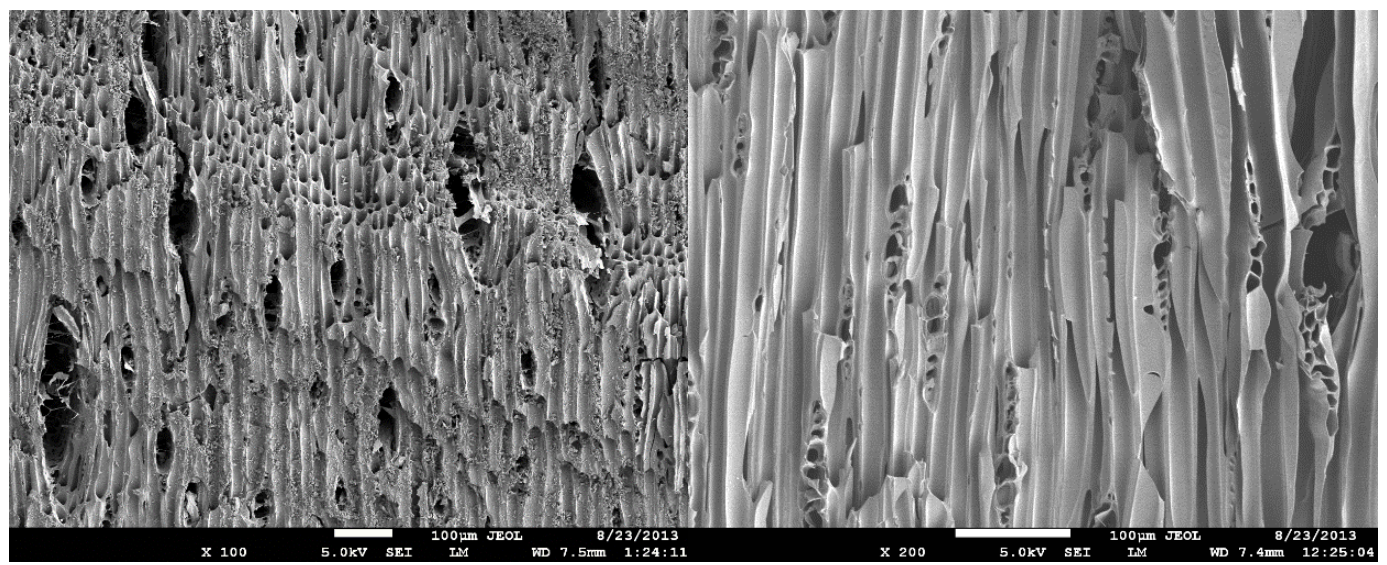

Fig. 6. Carbonized surface of the wood modified by DFF at magnification of $\mathrm{x} 200$
Fig. 7. Carbonized surface of the wood modified by APF-1 at magnification of x 200

\section{Discussion and processing of the results}

As is obvious from the data obtained, surface layer modifiers differently affect smoke formation capacity of wood.

The most effective is the DEP modifier, which chemically interacts with wood surface. The efficiency of the modifier is based on the elemental analysis data, before and after thermal degradation, where the stability of the phosphorus-containing compounds formed as a result of chemical reaction with the modifier is observed under the conditions of thermal degradation of the material.

As is obvious from the granulometric analysis data, the modifiers of wood surface layer significantly affect the quantitative properties of the smoke aerosols produced during thermal degradation of the modified wood. There is a decrease in the maximum size of the smoke aerosol solids, from $25 \mu \mathrm{m}$, in case of estimating the smoke produced by the thermal 
decomposition of the original wood, and up to $15 \mu \mathrm{m}$, in case of using DEP as a modifier of the surface layer of wood.

Depending on the modifier of the surface layer of wood, a change in the coagulation rate is observed. For particles with a radius of $0.2 \mu \mathrm{m}$, coagulation rate increases 4 times in case of DEP application as compared to original wood, which is determined by the nature of the modifier. With the increase in the particle radius, their coagulation rate with the application of DEP is significantly reduced, which is due to a small concentration of largesized particles and the smallest total mass of aerosol particles formed during the thermal degradation of the DEP-modified wood.

Based on the correlation of the data on the change in the smoke generating capacity and the size distribution of smoke aerosol solids, when using various modifiers, it can be concluded that the reduction of the smoke-generating capacity directly depends on the quantitative characteristics of the solid phase of the smoke aerosols.

The Gibbs thermodynamic potential of the wood surface was calculated based on the data obtained by the neutral drop method and the information on the surface layer structure before and after thermal degradation. As a result of the analysis of the results obtained, it was found that the change in $\Delta \mathrm{G}$ before and after thermal degradation for various modifiers correlates with the efficiency of the modifying action of the selected compounds.

Changes resulted from thermal degradation of the surface energy characteristics close to zero are typical for wood modified by DEP. A similar picture can describe the surface layer structure as stable. A different picture is observed in case of using other modifiers having a lower modifying efficiency. High values of the changes in the Gibbs energy $(\Delta \mathrm{G})$ before and after thermal degradation determine high surface activity in the process of thermal degradation with inelastic deformations characterized by formation of fractures and destruction of the surface layer. Such deformations are observed in the images of the surface layer of wood. The formation of smoke in this case is due to the thermal degradation of the internal non-modified layers of wood.

\section{Conclusions}

The kinetic parameters of sedimentation and coagulation of aerosols formed during the thermal degradation of modified wood depend on the nature of the modifier. In the phosphite series, DEP is the best modifier, which determines the highest decomposition rate of smoke aerosol. Instability of the surface layer is a key factor to form big-sized particles of smoke aerosol solids, which determines a significant decrease in visibility in the event of a fire. The nature of modifying agent affects the properties of the wood surface. Inelastic deformations with the formation of fractures can occur due to increasing internal energy of the surface. The decreased changes in the Gibbs thermodynamic potential characterize the modified surface stability; this is quantitatively determined by the total mass of the solid particles of the smoke aerosol disperse phase, and by the reduced maximum diameter of the particles. The modification of wood with phosphites therefore reduces the tendency to smoke-generating capacity, which determines the reduction in humans' death in the event of a fire.

\section{References}

1. A.M. Lukyanov, D.A. Korolchenko and A.G. Agapov, Fire hazards of the timber during bridge construction, World of Transport and Transportation, no. 4(42), pp.158164 (2012)

2. E.N. Pokrovskaya Preservation of monuments of wooden architecture with the help of 
organoelement compounds, ASV Publ., Moscow, 136 p. (2009)

3. R.M. Aseeva, B.B. Serkov and A.B. Sivenkov Burning wood and its fire behavior, State Fire Academy of Emercom of Russia Publ., Moscow, 262 p.(2010)

4. S.V. Shahov, I.N. Sukharev and S.Yu. Shubkin Aspects of thermal decomposition of wood with formation of smoke, Prospects for the development of fundamental and applied sciences. Proceedings of II International Scientific and Practical Conference, Prague, pp. 64-70 (2016)

5. C.J.Young and J.Moss Smoke inhalation: Diagnosis and treatment, Journal of Clinical Anesthesia, vol. 1, no. 5, pp. 377-386 (1989)

6. D.J. Shusterman, Clinical smoke inhalation injury: systemic effects, Occupational Medicine, no. 8(3), pp. 469-502, (1993)

7. S.D. Evstifeeva, Z.V. Tikhomirova and E.A. Samoshina, Carbon monoxide poisoning in fires, Advances in Current Natural Sciences, no. 9, p. 118 , (2013)

8. D. Canter, An overview of human behaviour in fires, Fires and human behavior, David Fulton Publisher, London, pp. 205-234., (1990)

9. J.L. Bryan, Implications for codes and behaviour models from the analysis of behaviour response patterns in fire situations as selected from the Project People and Project People II study programs. NBS-GCR-83-425. Washington, National Bureau of Standards, (1983)

10. M. Paabo and B.C. Levin, A literature review of the chemical nature and toxicity of the decomposition products of polyethylenes, Fire and Materials, vol. 11, issue 2, pp. 5570, (1987)

11. B.C. Levin, M.A. Paabo, J.M. Gurman and S.E. Harris, Toxicology of fire and smoke, Inhalation Toxicology. 2nd Edition. Chapter 10, CRC Press (Taylor and Francis Group), p.205-228, (2005)

12. E.G. Butcher and A.C. Parnell, Smoke control in fire safety design, E. \& F. N. Spon, London, 178 p., (1979)

13. P.G. Edgerley and K. Pettett, The effect of pyrolysis and combustion temperatures on smoke density, Fire and Materials, vol. 2, no. 1, pp. 11-17., (1978)

14. R.A. Orzel, Toxicologikal aspects of firesmoke: polymer pyrolysis and combustion, Occupational Medicine, no. 8(3), pp. 414-429, (1993)

15. E.N. Pokrovskaya, F.A. Portnov, A.A. Kobelev and D.A. Korolchenko, The smoke generation property and combustion products toxicity of wood which was modified by organoelemental compounds, Fire and Explosion Safety, vol. 22, no. 10, pp. 40-45 , (2013)

16. V.I. Timoshenko, N.N. Chernov and M.A. Lupandina, Macroprocess acoustic precipitation fine fumes, Izvestiya SFedU. Engineering Sciences, no. 9, pp. 220-223, (2013)

17. V.I. Bogillo, Influence of phase composition of atmospheric aerosols on the interaction kinetics with volatile impurities, Chemistry, Physics and Technology of Surface, vol. 2, no. 1, pp. 61-75, (2011)

18. A.E. Aloyan, Modeling of dynamics and kinetics of gas impurities and aerosols in the atmosphere, Nauka Publ., Moscow, 415 p., (2008)

19. Yu.G. Frolov Colloid chemistry course, Khimiya Publ., Moscow, 400 p., (1982)

20. J.H. Seinfeld and S.N. Pandis, Atmospheric chemistry and physics: from air pollution to climate change, John Wiley \& Sons, Inc., New York, 1248 p., (2006) 
21. A.E. Aloyan, A.A. Lushnikov, S.V. Makarenko, G.I. Marchuk and V.A. Zagainov, Mathematical modelling of the atmospheric aerosol transfer with coagulation taken into account, Russian Journal of Numerical Analysis and Mathematical Modelling, vol. 8, no. 1, pp. 17-30., (1993)

22. A.S. Tutygin, A.A. Shinkaruk, A.M. Aisenstadt and V.S. Lesovik, Ecological risks reduction in the production of concrete composites, Journal of International Scientific Publications: Ecology and Safety, vol. 8, pp. 54-61., (2014)

23. A.S. Tutygin, A.A. Shinkaruk, A.M. Aisenstadt, M.F. Frolova and T.A. Pospelova, Ways to increase and monitor bearing capacity of soils, Journal of International Scientific Publications: Ecology and Safety, vol. 7, part 1, pp. 37-45., (2013)

24. A.M. Ayzenshtadt, Thermodynamic optimization of the composition of rocks nanocomposites, Innovative materials and technologies for building industry in extreme climate. Proceedings of I International Scientific Conference. Northern (Arctic) Federal University named after M.V. Lomonosov Publ, Arkhangelsk, pp. 37-44, (2014) 